\title{
Autenticidade e religião: a Igreja Universal do Reino de DEUS E A ERA DAS CATEDRAIS
}

\author{
Rachel Aisengart Menezes
}

Dissemos que há na religião algo de eterno: o culto, a fé. Mas os homens não podem celebrar cerimônias para as quais não veriam razão de ser, nem aceitar uma fé que não compreenderiam de maneira alguma. Para propagar ou simplesmente para manter a fé, é preciso justificá-la, ou seja, fazer sua teoria.

Émile Durkheim

O livro A era das catedrais: a autenticidade em exibição demonstra a elaboração teórica a que Durkheim se refere na epígrafe acima. A obra se baseia na investigação que deu origem à tese de doutorado em Ciências Sociais (PPCIS/ UERJ) de Edlaine de Campos Gomes, pesquisadora arguta, que percebeu a importância do surgimento, crescimento e expansão da Igreja Universal do Reino de Deus (IURD), sobretudo no que tange às formas inovadoras de expressão em seu posicionamento no espaço público.

Na capa do livro, abaixo do título, consta o subtítulo: uma etnografia. Contudo, à medida que o leitor acompanha a imersão da pesquisadora na Igreja Universal do Reino de Deus, penetrando paulatinamente na polêmica em torno dessa igreja, sobretudo a partir do ano de 1995, quando se deu o início da investigação, ele se dá conta de que o estudo não se restringe a uma mera descrição etnográfica. Edlaine Gomes esteve lá: ela apreendeu o "esqueleto, a carne e o sangue, o espírito" (Malinowski 1986) da "aldeia" iurdiana. Ela observou rituais, reuniões, sessões de cura e eventos; entrevistou membros da IURD, visitantes, motoristas de vans, taxistas e vizinhos da Catedral. Assistiu a seus programas de televisão, acompanhou notícias da mídia, as polêmicas e os amplos debates em torno da apropriação de antigos espaços culturais da cidade (por exemplo, cinemas e teatros) para a construção de templos iurdianos. Além 
desse material, a pesquisadora contou com documentos oficiais da instituição, como seu Regimento Interno, Estatuto, seu jornal e variados textos escritos por suas principais lideranças.

O primeiro capítulo do livro enfoca os debates entre o discurso oficial da IURD e seus interlocutores, sejam eles os meios de comunicação ou a literatura sociológica que buscava, à época, um entendimento sobre as transformações no panorama e na dinâmica religiosa no Brasil. Conforme aponta a autora, davase então um forte interesse da imprensa, motivado pela surpresa diante da crescente onda de adesões à IURD e a outras igrejas pentecostais, além do amplo impacto diante das práticas associadas ao dinheiro. Por outro lado, como é possível observar em relação às pesquisas sócio-antropológicas sobre novos temas e questões emergentes, constata-se o uso - e, por vezes, a incorporação - de textos e artigos de cientistas sociais, em publicações oficiais da igreja, para demonstração de sua relevância e expressividade social. Além disso, as controvérsias conduziram ao uso de novas designações, concernentes às denominações pentecostais, por parte da imprensa e da própria instituição religiosa, provenientes da produção sócio-antropológica.

A história da IURD é apresentada ao leitor, no primeiro capítulo, a partir da explicitação dos debates provocados desde seu surgimento. $O$ processo de sua construção de identidade é demonstrado a partir de suas interações sociais com os interlocutores que criticam sua formulação e suas práticas. As trajetórias e as narrativas de membros da IURD, perceptíveis particularmente nos testemunhos públicos, evidenciam o "poder e a força" da igreja, no combate ao "Mal", seja ele concretizado na dor, no sofrimento, no "castigo" ou na perturbação por "espíritos malignos". Os relatos ilustram exemplarmente a transformação da vida dos que optaram pela inserção na IURD. Trata-se de uma busca por uma "igreja com poder maior" - poder que se reflete na elaboração de suas edificações, como as Catedrais da Fé.

A afirmação da identidade da igreja é analisada, no segundo capítulo, por intermédio da pregação do bispo Macedo, por ocasião do Jubileu de Prata da IURD, comemoração dos 25 anos de sua fundação. Um complexo processo é desvendado pela autora, a partir do exame da retórica em torno do "circuito da conquista", composto por quatro categorias: perseguição; revolta; sacrifício; e conquista. À perseguição religiosa é atribuída uma marca distintiva - uma "comunidade de sofrimento" -, que deve ser objeto de elaboração da memória coletiva da igreja. Assim, configura-se a formação de uma história de perseguições, merecedora de lembrança, que não deve se centrar na exclusão, mas em sua superação, para confirmação do "poder da conquista". O chamado circuito da conquista conta também com a noção de "pontos de contato", categoria que classifica os membros da IURD segundo seu grau de adesão.

O terceiro capítulo é dedicado ao exame da noção de "catedral", categoria 
que integra o quadro de reações da IURD, em oposição às acusações de não ser uma igreja autêntica. O posicionamento contrário da imprensa e de outros setores da sociedade se fundamentava no fato de que os locais de instalação de novos templos iurdianos (ou de outras denominações) "guardam o patrimônio cultural e a memória da cidade" (Rio de Janeiro). Ao mesmo tempo, observavase, à época - como ainda hoje -, a multiplicação de denominações e de igrejas pentecostais, com significativa transitoriedade e fluidez, por suas mudanças frequentes de endereço.

A análise da polêmica em torno desse tema evidencia dois aspectos: o material, concernente à ocupação física e espacial; e o imaterial, que se refere à intervenção na memória e na tradição da cidade. Para muitos pensadores das ciências sociais daquele momento, a IURD, com sua ocupação dos espaços, consolidava um mercado da fé. No entanto, para a igreja, a autenticidade se fundamenta na construção das catedrais. Um marco aí é estabelecido: um antes e um após a "era das catedrais". Trata-se de um posicionamento que indica continuidade, permanência e consolidação da IURD, tanto no tempo, quanto no espaço.

No processo de institucionalização da igreja apresentam-se dois tipos de autenticidade: um aurático e outro não aurático. Enquanto, na primeira modalidade, o tempo é valorizado, na autenticidade não aurática se dá o contrário: sua marca é espacial. A percepção da catedral como um monumento indica uma das diferentes formas de implementação iurdianas de seu "projeto de igreja consolidada". Nesse sentido, a catedral se torna uma referência na paisagem urbana, tanto para a própria instituição como para seus membros. Edlaine Gomes se detém sobre a concepção arquitetônica das catedrais, planejadas para se tornarem "lugares de memória", em estilo "eclético com referência ao neoclássico".

Monumentalidade e consolidação estão imbricadas nessa dinâmica, assim como as reiteradas referências ao "Israel mítico" ou à "Terra Santa". Os objetos provenientes de Israel integram os rituais iurdianos e, portanto, são mais do que referências simbólicas, ao contribuírem à materialização do projeto dessa igreja. "Mais do que um sonho, conhecer Israel é uma necessidade de todo cristão", afirma o bispo Macedo em publicações da IURD. Desse modo, um mito de origem - que, aliás, não é exclusivo dessa igreja - é afirmado e reafirmado, em discursos, rituais e objetos, para demonstrar a identificação dos iurdianos com o "povo sagrado". A análise desenvolvida evidencia que a memória, remetida a um tempo mítico ou à "Terra Santa", atua como suporte para a noção de autenticidade elaborada pela IURD.

A etnografia da Sede Mundial da IURD, com suas características arquitetônicas, localização e descrição dos espaços são abordadas no quarto e no quinto capítulos. Guiado pela descrição da sede, o leitor ingressa nos lugares e transita em um novo território simbólico, tendo, passo a passo, um maior contato 
com a intenção de grandiosidade do projeto, que, por exemplo, reproduz logo na entrada da principal edificação uma cópia do "Muro das Lamentações" existente em Israel.

O caráter de autenticidade não aurática da construção, com a recriação da "verdadeira Jerusalém" em maquete, como provavelmente era na época de Jesus, expressa o "amor à Terra Santa". Trata-se de uma reprodução, percebida pelos iurdianos como "mais autêntica do que a original". Os lugares são, portanto, autênticos e sagrados na mentalidade dos fiéis. Ao mesmo tempo, também há espaços de sociabilidade para todos os passantes, planejados para serem locais agradáveis e confortáveis, voltados para o lazer de famílias em finais de semana. $\mathrm{O}$ projeto iurdiano materializa o acolhimento e demarca os limites entre o profano e o sagrado, havendo mesmo uma passagem que efetua essa transição.

O quinto capítulo é dedicado à análise das práticas cerimoniais e ao exame das comemorações do Jubileu de Prata da IURD, na sua Sede Mundial. Nesse ponto do livro, a descrição das sessões de descarrego, de cura, de libertação e dos batismos, no amplo espaço da nave principal, explicita a articulação das categorias centrais da cosmovisão iurdiana, em suas práticas rituais: a fé é "posta em ação", por intermédio dos "pontos de contato", reiterando a consolidação de um espaço e de uma memória sagrados.

O evento comemorativo dos 25 anos de existência da IURD foi organizado não apenas para marcar uma data, mas para produzir e divulgar a imagem de uma igreja com uma história, uma organização religiosa que se quer autêntica, que "veio para fazer a diferença". A autora analisa as maneiras utilizadas pela IURD para demonstrar seus traços distintivos em relação a outras igrejas, na construção de seus templos monumentais, que pretendem possuir um "poder maior", na criação de sua memória e na formulação de novas designações para o "Mal", alvo combatido nas práticas rituais.

A pesquisa, iniciada em 2000, se mostra de extrema atualidade, o que é constatado por Edlaine Gomes em sua apresentação do livro. As investigações realizadas pela autora nos anos que se seguiram à defesa de sua tese evidenciam a amplitude e a profundidade de sua reflexão no campo de estudos da dinâmica religiosa no Brasil. Mais do que o acesso a um amplo conjunto de distintas perspectivas teóricas, a pesquisadora efetua descrição e análise densas, sem incorrer em posicionamentos favoráveis ou contrários à IURD em seu comprometimento político ou em relação às críticas veiculadas pela mídia.

Ao término da leitura o leitor se dá conta de que o fato social total, nos termos maussianos, foi abordado e tratado detalhadamente. A capacidade da investigadora de se aproximar e se distanciar de seu objeto de pesquisa, seja no exame dos discursos nativos ou oficiais da IURD, seja na apresentação dos debates sobre a ocupação de espaços urbanos pelas igrejas ou, ainda, relativamente à produção das ciências sociais a respeito do tema, é responsável pela qualificação 
do livro A era das catedrais como uma valiosa nova referência nas pesquisas sobre a IURD. Nesse sentido, sua leitura é de grande serventia para o pesquisador que escolher essa denominação religiosa ou qualquer outra de fé pentecostal/ neopentecostal como objeto de investigação.

\section{Notas}

${ }^{1}$ MALINOWSKI, B. (1986), "Os argonautas do Pacífico Ocidental”. In: R. E. Durham (org.). Malinowski. São Paulo: Ática.

Rachel Aisengart Menezes (raisengartm@terra.com.br) Professora Adjunta do Instituto de Estudos em Saúde Coletiva da Universidade Federal do Rio de Janeiro. 